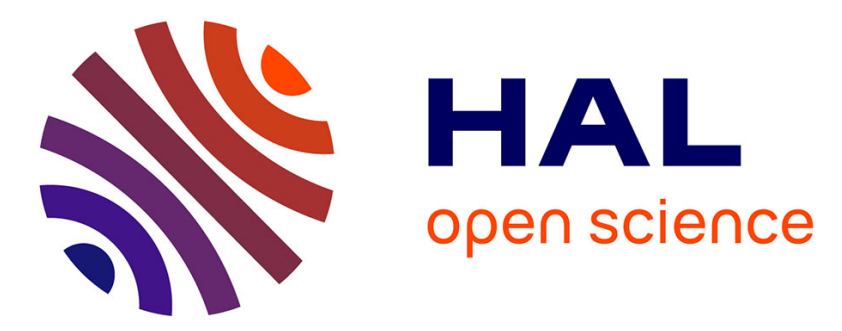

\title{
Design process perceived as an information process to enhance the introduction of new tools
}

Carole Bouchard, Améziane Aoussat

\section{To cite this version:}

Carole Bouchard, Améziane Aoussat. Design process perceived as an information process to enhance the introduction of new tools. International Journal of Vehicle Design, 2002, 31 (2), pp.162-175. hal-00915209

\author{
HAL Id: hal-00915209 \\ https://hal.science/hal-00915209
}

Submitted on 6 Dec 2013

HAL is a multi-disciplinary open access archive for the deposit and dissemination of scientific research documents, whether they are published or not. The documents may come from teaching and research institutions in France or abroad, or from public or private research centers.
L'archive ouverte pluridisciplinaire HAL, est destinée au dépôt et à la diffusion de documents scientifiques de niveau recherche, publiés ou non, émanant des établissements d'enseignement et de recherche français ou étrangers, des laboratoires publics ou privés. 


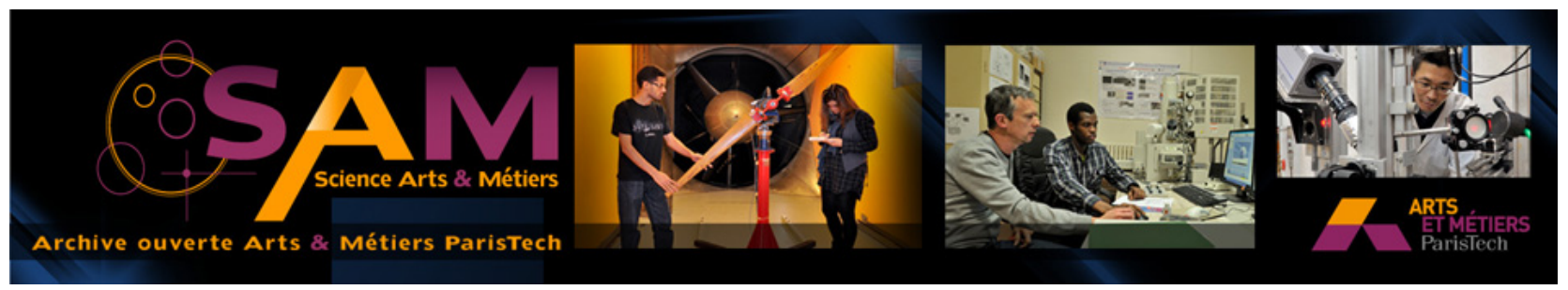

Science Arts \& Métiers (SAM)

is an open access repository that collects the work of Arts et Métiers ParisTech researchers and makes it freely available over the web where possible.

This is an author-deposited version published in: http://sam.ensam.eu

Handle ID: .http://hdl.handle.net/10985/7609

\section{To cite this version :}

Carole BOUCHARD, Améziane AOUSSAT - Design process perceived as an information process to enhance the introduction of new tools - International Journal of Vehicle Design - Vol. $31, n^{\circ} 2$, p.162-175 - 2002 


\title{
Design process perceived as an information process to enhance the introduction of new tools
}

\author{
C. Bouchard ${ }^{*}$ and A. Aoussat ${ }^{\dagger}$ \\ *Laboratory CPN-ENSAM, 151 Bd de l'Hôpital, 75013, Paris. \\ E-mail: carole.bouchard@paris.ensam.fr \\ ${ }^{\dagger}$ Laboratory CPN-ENSAM, 151 Bd de l'Hôpital, 75013, Paris. \\ E-mail: améziane.aoussat@paris.ensam.fr
}

\begin{abstract}
Our research adds its weight to collaboration between companies and the research laboratory in conceiving new products (CPN/ENSAM Paris). Our work focuses on industrial design, creativity and innovation. In this paper we have formalized the design information process to build new tools of communication, decision-making and creativity for the different players in the design process.
\end{abstract}

Keywords: computer aided design tools, design process, information process.

Reference to this paper should be made as follows: Bouchard, A. and Aoussat, A. (2002) 'Design process perceived as an information process to enhance the introduction of new tools', Int. J. Vehicle Design, Vol. X, No. Y, pp. 1-14.

Biographical notes: Carole Bouchard is lecturer and researcher and obtained his doctorate in Industrial Engineering in 1997. She made her thesis for a European car supplier in the field of the automotive design on the subject modelization of the care design process, application in bumpers design. Carole Bouchard practices of three years in the laboratory of new products desigtn and innovation of the National Superior School of Arts and Crafts as contractual professor. She works today on the thematic of the creativity and innovation, as well as on a subject she develops for three years concerning design watch.

Ameziane Aoussat is the head manager of the New Products Design Laboratory of Paris at the National Superior School of Arts and Crafts since 1996. He practices as lecturer and researcher since September, 1995, having been a research engineer before. Ameziane Aoussat pilots research projects and was qualified in the functions of Professor of Universities since March, 2000 on the following subject: contribution to the modelization of the products design process in the mechanical specialty. He obtained his doctorate in 1990 about the contribution in innovation as a plural approach. Today his mission consists in the management of the overall research in the CPNI laboratory and in the stimulation of the education and research activities as well as industrial research collaborations.

*Corresponding author. 


\section{General Introduction}

Today, the design process of industrial products has been transformed both by earlier computerization and production of design information aimed at clarification and memorization of the earliest phases such as marketing, design, etc.

This evolution is based on the context of variety and reaction capability defined by Midler [2] where initial phases are modified by both inter-professional synergy which takes place increasingly earlier in the process and by the introduction of new digital tools especially in the early phases of design projects. We believe that the introduction of new digital tools must be based on improved formalization of the early phases in the design process. In this respect, the design process can be seen as an information production process, i.e. a set of successive cycles of design information with the manipulation of an increasing number of concrete representations of physical objects to reach the Final Solution, with a problem space being set in a solution space for each cycle. Results in this paper involve the formalization of input data as intermediate representations from the technical specifications. Indeed, the design process can be seen as an information process where the design problem space will be gradually transformed into a solution space.

\section{Modelling the information process in design}

Finalized intangible information is transformed step by step into tangible information by way of mental representations (transfer of information: shaded area). Birtley [5] proposes a generalization of the theory of information: 'information is what forms or transforms a representation'. A comparison can here be made between the transformation of images and the representations generated by messages containing information. The information modifies the representations so communication can be measured by measuring these changes. A physical system supplies an

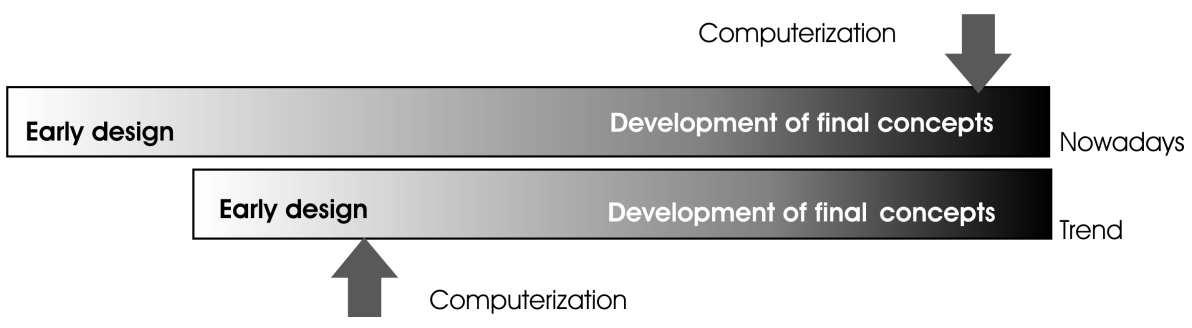

Figure 1 Evolution of the computerization process in engineering design [1].

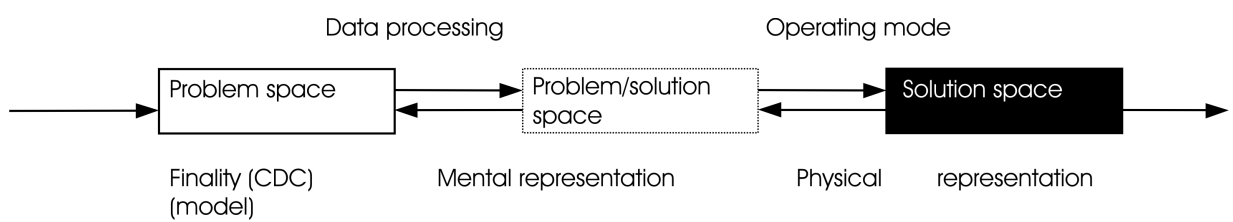

Figure 2 Description of a materialization cycle [3]. 


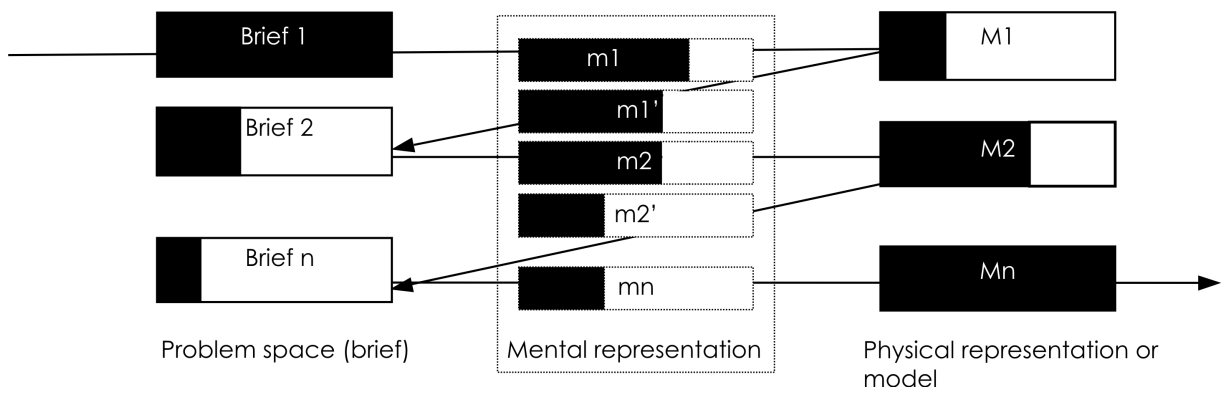

Figure 3 Representation of the diachronous design process (adapted from Lebahar) [3] [4].

external memory modifying the problem of perception in a decisive way. The space issue (expressed goals), together with the solution space (physical representations), are given precision by the production of signs - verbal codes in the case of briefs and formal codes in the case of solutions. Each cycle - Brief1, m1 and M1 - matches a state of representation. The evolution of the Brief is defined by the transformation of ends into purposes, purposes into objectives, objectives into criteria, the criteria as increasingly concrete technical specifications. Mental representation corresponds only partially, like the physical model.

By defining models within a set of attributes, process $\mathrm{P}$ is characterized by the following succession of cycles: Brief1 M1 (A11, A12, A1n), Brief2 M2 (A21, A22, A2n) and BriefNMN (An1, An2, Ann) ${ }^{1}$. The process develops a system of information (objectives) in a signs system (solutions) in which recognition and evaluation enable the production of new signs. Signs emanate from the process of the mental make-up of an imaginary object being changed into an easily comprehensible object. The design process fits into the general plan of the process of conception presented above. The solution space, in the context of the activity of design, is especially marked by the changeover of iconic signs to plastic signs. The solution space is established by a succession of modelled forms. Thus, the diachronous design process is characterized by the gradual overall reconfiguration of a space problem (brief) into a space solution (3-dimensional model), according to a recursive cycle in which partial transformation takes place from the space problem to intermediate solution spaces at every representation level. At any time in the process, designers must be able to assimilate and deal with a large volume of information without losing sight of objectives. This equivalence characterizes the problem/solution space. The design process consists in reducing abstraction through the use of various successive levels of representation integrating increasingly numerous constraints. It is characterized by Wang as concepualization including an iterative cycle of mental solutions shown with a given problem [6], where (1) the selection of a solution or partial solutions enable the limitation of uncertainty, and keeping in mind the necessary level of vagueness in modifications during subsequent phases [4], (2) new constraints are then added by preserving shape and initial ideas, with (3) the display of a new physical representation generating new ideas and new solutions. Lloyd and Scott describe the design process as generative, deductive and evaluative statements in the activity of design [7]. We consider the design process can be based on the three following phases: 


\subsection{Generation phase}

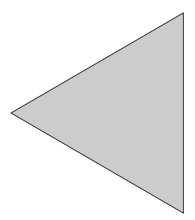

This phase consists in the generation of new ideas and new solutions: by means of numerous mental images and from brief data and other information contained in any design project, designers can generate physical representations and physical solutions as 2-dimensional and 3-dimensional models.

This requires the use of manual or digital tools, depending on designer skills and on corporate culture. This phase can be performed in accordance with various 'trends analysis' and 'applied creativity' methods. Trends analysis enables formalization of formal attributes linked to particular environments before the early sketching phase. Applied creativity enables the generation of a large volume of ideas, possibly even including the points of view of other non-designer players (ergonomists, engineers, etc.). The generation phase is an open phase.

\subsection{Information phase}

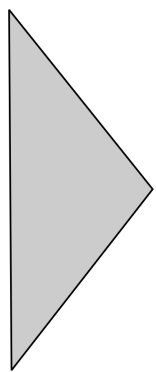

Designers and other players in the design process integrate many categories of information that will be gradually formalized as design solutions throughout the design process. This represents the information contained in the brief and emanates from sources of inspiration and data researched by the designers to complement the brief.

According to Prost, the choice of constraints is furthermore a process fundamental to the activity of design [8]. The information and data integrated by the designer can be categorized into information connected to the project, passed on by other players or sought by the designer and the designer's own information or that stemming from the designer's interactions with the surrounding world (notions of references as influences and sources of inspiration) and sometimes dominating over the information connected to the problem. This is both an open and closed phase. 


\subsection{Evaluation and decision phase}

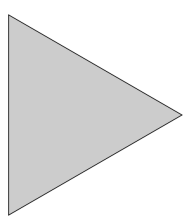

The choice of the right design solutions to be developed physically is achieved by an evaluation and deduction process. It uses criteria from the initial or reviewed brief to help choose the best solutions. The Evaluation and Deduction phases are analytical phases. Many methodological tools can back up these phases such as functional analysis and semantic differentiation. This phase is a closed phase.

Quality Function Development and Functional Analysis allow the generation of functional criteria linked to the primary main functions and the secondary constraints functions. These criteria can be quantified and used during the evaluation of many solutions in order to record them and select the final solution(s).

Designers and non-designers do not posses the same differentiation capability [9]. Semantic differentiation or semantic mapping is another evaluation/prediction model determined by a visual evaluation of the image of products. It consists of a full representation of the product space produced as per two highly distinguishing semantic axes. The semantic differential establishes a quantitative relationship between the Shape of the product (dimensions) and the evaluation of its significance according to semantic attributes. Application of semantics helps designers to understand and evaluate their own communication models. Communication is successful by matching the response to the signal. Most industrial designers feel that they control the process. They know what they wish to say and are certain that they have the tools to make the correct visual statement. Unfortunately, little time is spent for the understanding of the remaining two components of the scenario reception and response and this is where the breakdown usually occurs.

\subsection{Description of an information cycle}

All information cycles contain an informative phase, a generative phase and a decision-making phase (evaluation-selection) whose outcome is an intermediate representation that will be used for the transmission of project information to the other design process players and - compared with the previous cycle - as a more concrete informative mass.

The efficacy of each phase will influence the whole process and the three phases should be of equal value to achieve optimal results. If one of them fails, the general process and of course the final result will fail. Currently, software is being assessed to assist designers in the digital realization of the three phases. One advantage would be the possible memorization of the project design data and another the possibility of achieving fast modifications capable of being transmitted to and printed by consumers physically in quasi real time. For the information phase, numerous digital iconic Databases are available. For the generation phase, Computer Aided Design systems are being introduced or more recently, purpose-built automotive Computer 

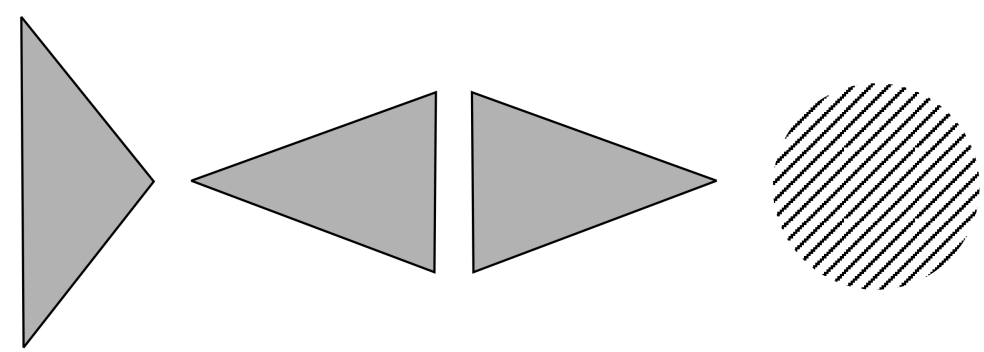

Intermediate

representation
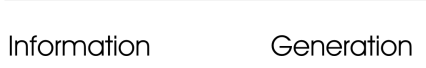

\section{Decision}

Communication

Figure 4 Description of an informational cycle.

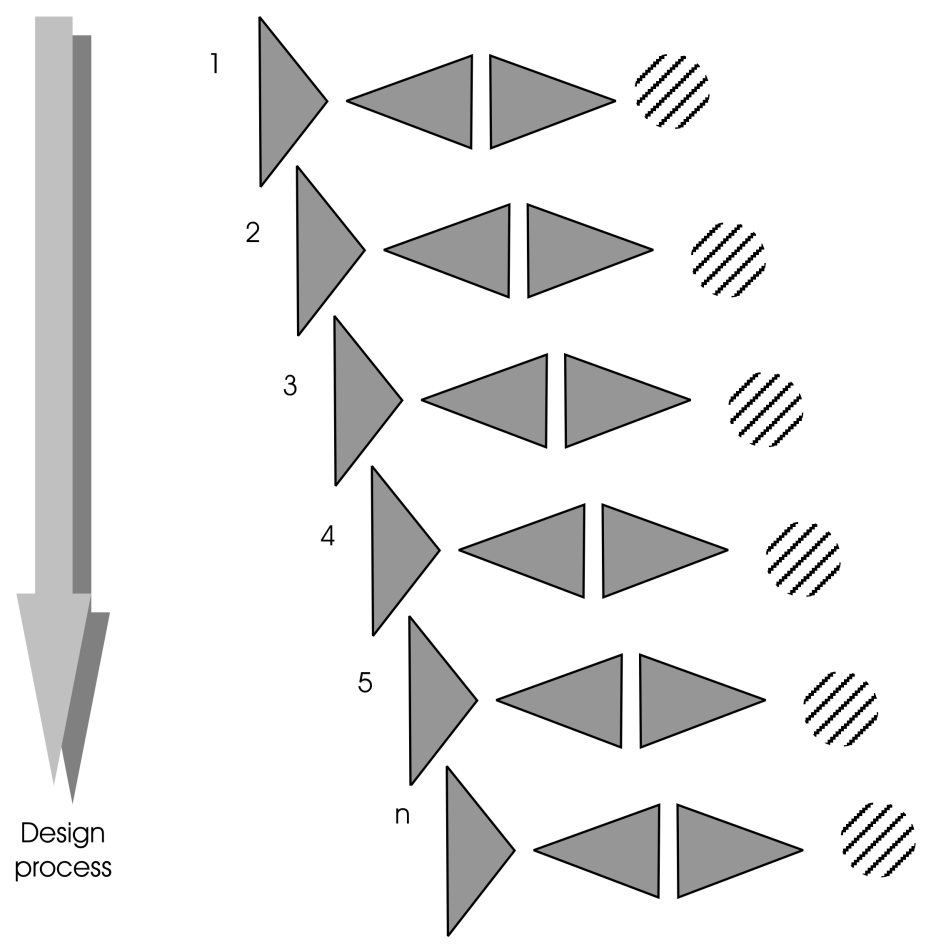

Figure 5 Description of the informational process in design activity.

Aided Styling systems. The latter will be presented in this paper for their relevance to design, the purpose of our study.

\subsection{Description of the general information process}

Formal and informal information used in the design process is increasingly formalized on a individual or group basis in the form of verbal transcriptions, mapping or modelling and then as successive project syntheses. These various forms 
Formalization

Digital

Communication

memorization

materialization

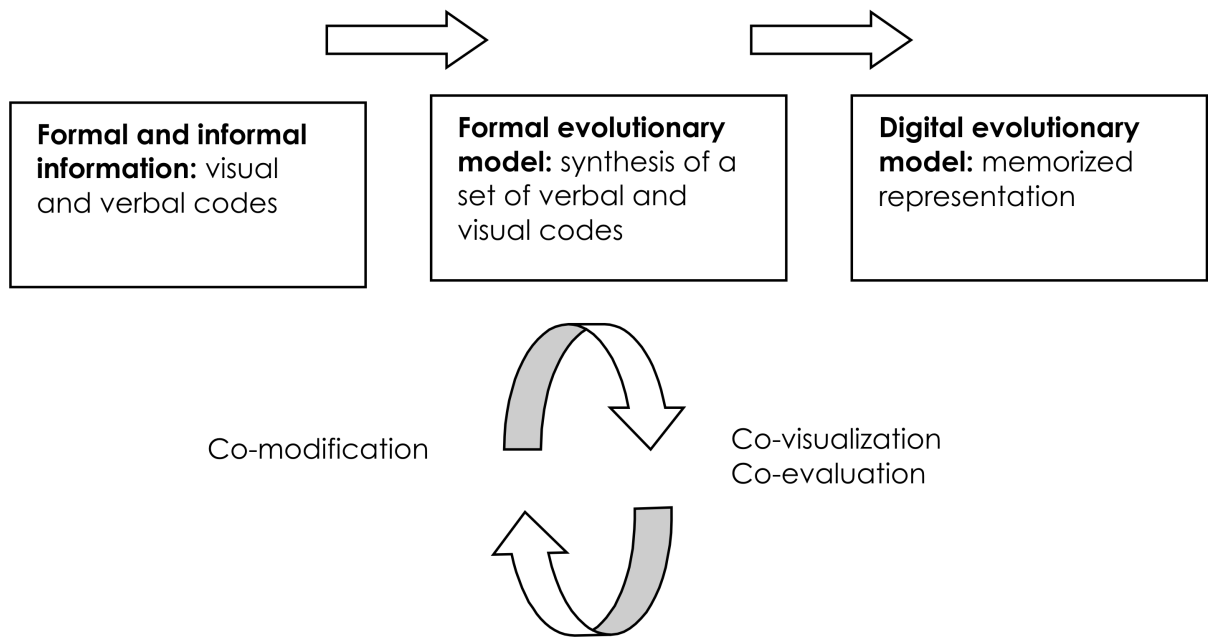

Figure 6 Informative needs in design [10].

of information together make up a common representation of the project that we have called the 'evolutionary model' based on the semiotic and functional brief of the concept to be developed. Storage and recording of the model can be achieved in various ways, ultimately resulting in an evolutionary digital model. The latter is designed for communication in time and space with possible physical and tangible information production by means of printing or prototyping. In Figure 6, digital information tools are shown to be associated, (1) with simultaneous or deferred validation, (2) with digital memorization, (3) with communication and (4) with execution. Execution tools primarily involve prototyping technologies: CAS-CADCAM (Computer Aided Styling, Computer Aided Design and manufacture, Rapid prototyping, etc.).

\section{Current situation of digital tools in design process}

\subsection{Description of conventional styling}

Design problems are characterized by the simultaneous building of problems and solutions, complicated by incomplete data and a great variety of solutions. The design process reduces abstraction by the use of many representation levels including an increasing number of constraints. In the above process, shape is more important than measure. The designer seeks the best shape, the best idea and then integrates measurement constraints. After preliminary sketches, many general solutions do not apparently lose their relevance. The selection of solutions or partial solutions allows the limitation of uncertainty, bearing in mind the blur level necessary to permit modifications in the next stages [4]. New constraints will then be added while 
retaining the initial general shape and idea. The visualization of a new representation level will generate new ideas for new solutions. This kind of drawing has to be quick enough and must be confined to the relevant information (detail level) to solve the problem [4]. It is necessary to have a definition of the needs of designers in terms of representation and to define the links between a physical representation and a mental or sensorial representation mode. Drawing is the image of thought [11]. It is important to consider that other operators like consumers or engineers have to appear earlier in the design process involving border-crossing relations. Representations are a physical visual medium for the simultaneous generation of new ideas and for 'structuring' (fixing thought). They are used by the designer himself and communicated and interpreted by other automotive supplier operators for transformation or by appraisers for assessment. In the design process, some steps are validated by considering their appropriateness to the brief. This allows for the necessary level of formalization for pedagogical and communicatory reasons. Each stage also means the gradual integration of new constraints (remaining creative during solution building) and the assessment by other actors of the appropriateness of the concept to the brief using the matching representation level. Evaluation in its various parts remains a critical stage: how to judge a drawing without being subjective in relation to the problem. In order to match the brief, the assessment must be achieved with respect to the image attributes and the functional attributes. But, the expressed 'feeling', a word often used by designers, together with the graphical qualities and detail level (precision of thought) affect considerably the perception of these attributes. The greater the degree of formalization of possible attributes, the easier the assessment.

\subsection{Main problems encountered with the use of conventional computer aided design tools}

Development of new Computer Design Tools should take into account the current list of problems being compiled with conventional Computer Aided Design Tools. The results of an inquiry in 1997 by 40 stylists (transport design specialists and students) can be summed up as follows [12]:

- Software has to fit traditional designer strategies - it should not require new designer strategies. These could interfere with the 'natural' designer activity, e.g. 'selecting elements and linking them together', except where the matching function offers advantages.

- Association of 2-dimensional with 3-dimensional is problematic. Either the software needs a 3-dimensional form of reference to project 2-dimensional sketches using the projection approach or the modelling is difficult because of the low 2-dimensional sketch input, using the 'free curves' approach. In design, an iterative method (sometimes with a manual modeller) should be used, first in 2-dimensional, then in 3-dimensional, and so on.

- Representation requirements: the CAD monitor is not large enough to display several concepts simultaneously, or scale vehicle models. Likewise, a large screen is required to simultaneously display a global representation and a more detailed representation. This presents the difficulty of visualizing the model and a 3-dimensional object in a 2-dimensional space. In a 3-dimensional computerized 
representation space it is difficult to assess the real position of a point in relation to its identification marker.

- Manual manipulation: a direct input system with a mouse or even with an optical pencil is inaccurate because of imprecise positioning in the pointer space and because of the matching computerized line dependent on specific pixels. Moreover, the system response time requests that designers receive complementary training to enable their proprioceptive representation to fit their mental image.

- Decision-making: software of this type enables early confirmation of information from the designer.

\subsection{Description of new computer aided design tools}

Digital tools currently tend to participate increasingly earlier in the design process. In major companies, CAD tool interfacing currently takes place at the stage between the representation of final concepts and their development. CAD tools can also be used earlier than this phase in order to produce a realistic rendering in an environment integrating colors, lights and backgrounds. Conventional digital tools such as Alias or CDRS used for the generation of computerized images are often sourced from design to engineering department information flows with the aim of comparing different variants for cost before making a selection. They produce a mathematical definition of the design that can be directly integrated into rapid prototype producing media. Wardle states, 'they eliminate the need for certain loops of model generation and consistently accelerate the activities of concurrent engineering to reduce development time' [17]. Besides, concept variants can be compared for the purposes of selection.

But interest is now being shown in the integration of CAD tools at the initial ideas and drafting stage. One result is the development of new software styling applications at the research stage. 'Computer Aided Styling tools' also tend to back up the information, generative or decision-making phases. They are based on a precis analyses of designer activity, including their conscious awareness and the 'conceptualization' containing an iterative cycle of mentally visualizing solutions with a given problem [6].

What is more, the design process occurs through the increasing use of co-software incorporated in a recently adopted method called Computer Aided Collaborative Work or computer supported collaborative work (CSCW), involving software packages evolving in shared environment. These tools maintain a wide vision of the work while optimizing the ratio of mutual prescription among designers [18] in situations of conceptions characterized by a strong interdependence among operators [19]. Co-conception software packages favour the co-operation and co-ordination of convergent activities through careful reflection and fast efficient decision-making. This software integrates Data Basis Management systems that can be very useful for designers.

We shall here set out the most relevant design digital tools we found in European literature under the heading of Computer Aided Styling Tools. The first, second and third chapters mostly deal with the generative aspect while the fourth chapter covers the evaluative part of designer activity. Some styling phases can indeed be automated to a certain degree. 
Table 1 New digital tools for the Information/Generation/Decision phases in the design process.

\begin{tabular}{|c|c|c|c|c|}
\hline Phase & Activities & $\begin{array}{l}\text { Prevailing cogni- } \\
\text { tive need }\end{array}$ & Type of tool & Sources \\
\hline Information & $\begin{array}{l}\text { Definition of the } \\
\text { problem area } \\
\text { Research of } \\
\text { inspiration } \\
\text { sources, references } \\
\text { and influences, } \\
\text { matching them to } \\
\text { the brief }\end{array}$ & Investigation & $\begin{array}{l}\text { Design watch } \\
\text { database }\end{array}$ & $\begin{array}{l}\text { Credoc [13] tatung } \\
\text { company [6] }\end{array}$ \\
\hline \multirow[t]{4}{*}{ Generation } & $\begin{array}{l}\text { Formalization of } \\
\text { external or } \\
\text { internal technical } \\
\text { solutions or part } \\
\text { of solutions }\end{array}$ & $\begin{array}{l}\text { Vizualisation } \\
\text { 2-dimensional/ } \\
\text { 3-dimensional } \\
\text { sensory } \\
\text { communication }\end{array}$ & $\begin{array}{l}\text { Computer aided } \\
\text { styling based on } \\
\text { morphology, } \\
\text { interpolation and } \\
\text { geometric } \\
\text { transformation }\end{array}$ & $\begin{array}{l}\text { Tatung company } \\
\text { [6] }\end{array}$ \\
\hline & $\begin{array}{l}\text { Modification of } \\
\text { solutions or parts } \\
\text { of solutions }\end{array}$ & & $\begin{array}{l}\text { Computer aided } \\
\text { styling as fast } \\
\text { shape design using } \\
\text { a modeller based } \\
\text { on sketch input } \\
\text { with an object } \\
\text { data structure }\end{array}$ & $\begin{array}{l}\text { Delft university } \\
{[20]}\end{array}$ \\
\hline & & & $\begin{array}{l}\text { Computer aided } \\
\text { styling based on } \\
\text { sketches using a } \\
\text { combination of } \\
\text { extrusion and } \\
\text { projection } \\
\text { techniques }\end{array}$ & $\begin{array}{l}\text { Coventry Univer- } \\
\text { sity [14] }\end{array}$ \\
\hline & & & $\begin{array}{l}\text { Computer aided } \\
\text { styling based on } \\
\text { the generation of } \\
\text { aleatory forms by } \\
\text { aleatory }\end{array}$ & $\begin{array}{l}\text { Sapporo school of } \\
\text { the art [15] }\end{array}$ \\
\hline Decision & $\begin{array}{l}\text { Individual evalu- } \\
\text { ation of solutions } \\
\text { Collective } \\
\text { evaluation of } \\
\text { solutions Selection } \\
\text { Deduction }\end{array}$ & Deduction & $\begin{array}{l}\text { Automatic } \\
\text { semantic analysis }\end{array}$ & $\begin{array}{l}\text { Compiègnes } \\
\text { University [16] }\end{array}$ \\
\hline
\end{tabular}

The Computer Aided Styling tools we were shown in various research laboratories provide the following advantages:

- They tend to reduce the main problems quoted in $\S 3-2$, by taking into account the natural strategy of designers and facilitating the link between 2-dimensional and 3-dimensional generation, offering improved visualization and the possibility of plasticity usually provided by conventional tools in the form of 'pen and paper' or 'markers' but not by Conventional Computer Aided design Tools. 
- Some are connected to Databases allowing direct partial or full integration of 2-dimensional or 3-dimensional objects in new representations following the same process as the natural mental process of the designers when they integrate sources of inspiration in the generation of new representations.

We shall then present a case study of an investigation tool for designers aimed at facilitating their information phase work.

To conclude, we shall extrapolate current trends to explore the prospects of developing new tolls.

\subsubsection{Computer aided styling based on morphology, interpolation and geometric transformation (project backed by tatung company and the national science council in taiwan)}

This software affords computerized assistance in the investigation process by stylists. It enables the expression of much generated thinking. It can be based on a morphologic approach: the possibility of generating a large number of combinations with a systematic exploration of different architectural configurations of functional modules. This kind of approach is particularly interesting for exploring the modularity concept in car design. Other methods are based on the interpolation of shapes or 'morphing' originating from mental images representing a particular type of object. These systems can be applied to various areas of design to combine two different shapes at a certain level of combination. This last process takes its inspiration from the natural mental process of stylists.

\subsubsection{Computer aided styling as fast shape design using a modeller based on sketch input with an object data structure system (developed at the delft university of technology [20]}

The Fast Shape Designer enables the simultaneous generation of ideas and sketching by the designer. Initially, designers can either feed in an old model and select curves from a library to create a new model or sketch a new curve with the sketch Manipulator. They must then reposition the curves in a 3-dimensional object space and identify the topology to the curve mesh by linking curves together.

The final stage consists of filling in the holes in the curve mesh with smooth patches and changing the patches iteratively by sketching or repositioning curves. The system is completely interactive and does not require precise values during sketching. It is closer to the architectural approach (2-dimensional->3-dimensional) than to the sculptural one, because it is based on curves sketched by hand in a freely positioned plane.

\subsubsection{Computer aided styling based on the generation of aleatory forms by aleatory generation softwares (sapporo school of the arts-japan)}

A form is considered to possess emergent factors and each factor its determining and selecting processes. An infinite combination of factors can be obtained by introducing random decisions in the process [15]. In order to generate aleatory texture forms, the following emergent factors have been defined: texture generation functions, attributes of basic geometric elements, background colour, painting times, and displacement distances of geometric elements. 


\subsubsection{Computer aided styling based on sketches using a combination of extrusion and projection techniques (developed at coventry university - VIDE center)}

At Coventry University, a large research project in collaboration with car manufacturers (the Digital Mock-up Program) 'concentrates on new modelling methods for the car industry, in order to support the design process from conception to manufacturing and avoid the current practice of linking a variety of incomplete and expensive models of components and assemblies for design and evaluation purposes'. The initial stage deals with the integration of Computer Aided Styling in the process enabling early validation and manufacturing phases through the use of a combination of enhanced sketching techniques, novel modelling approaches and rapid prototyping technologies. The new software enables the designer to 'produce implied 3-dimensional computer models from 2-dimensional automotive concepts sketches using a combination of extrusion and projection techniques'.

\subsubsection{Computer aided information research in design (project backed by the research centre for the study and observation of living conditions in collaboration with renault, paris)}

Designers complement brief data by researching visual information. A Management system of investigation of the relevant information can be of assistance on condition their needs are integrated in terms of researched items, presentation size (format) of data, or research strategies. The study of new software by the Research Centre for the Study and Observation of Living Conditions shows that the informative vagueness at the point of departure emanating from the $\mathrm{CDC}$ can constitute a designer creativity domain. But, if the informative contribution of the software is detailed, its appreciation is accompanied by designers having an impression of a 'dispossession of the capacity for imagining and sensibility (...). Designers have a certain difficulty to accept an already defined environment, and fear being dispossessed of this part of the search for information which is an integral part of their work [13]'. Indeed, this tool tends to automate their activity. On the other hand, if the current models produced often lose the formal allegiance of designers to some extent throughout the design process, the use of digital Trends Data base tools can enable the direct extraction of element (textures, formal motives, 'morphings') and their direct application to the digital model, the insertion of the model in environments to highlight harmonies, and direct realization of the Formal characteristics of the real model by rapid prototyping.

\section{Perspectives}

A general digital tool offering a module of Computer Aided Styling in an environment where it is possible to recall pre-existing elements would allow a reduction in the number of models and consequently preference for the evaluation phases. Such a tool thus combines time reduction and cost reduction.

The appearance of future tools can now be expected with the new Computer Aided Design Tools based on object data structuring. Object data structuring allows the integration of numerous modules into the same software system - data (static) and procedures (dynamic) that manage them are grouped within the same entity - the 
object. The object is defined by its behaviour (not by its structure). Every new object has to be functionally explained. Chirowsky gives an example through the realization of CAADIE software: 'objects are not enounced in terms of form but in terms of functions and performances [21]'.

Functionnal modes of object enable the realization of performance analysis and their match with brief constraints (measurement controls, kinematics calculations, etc.). Even if CAD tools are not yet ready to be used in very early design stages, they promise time-saving (shorter CAD/CAM link) with greater flexibility (ability to store models and to modify them) and a considerable communication impact (availability on the Internet, reproduction on different scales). On the other hand, not only can they increase representation realism with the possibility of producing very complex shapes and of displaying them in specific dynamic environments, but they can also perform representation and evaluation with fast 3-dimensional to 2-dimensional representation generation. With object data structuring they could enable multiple evaluation from the brief in a unique environment effectively meaning evaluation in real time (aerodynamics constraints, safety constraints, package constraints, semantic matching by means of specific configurations, kinematics analysis, etc.). During sketching, traditional tools are considered superior with respect to rapidity of execution, fidelity to ideas and freedom of creation. CAD tools must provide improved sensorial relations between designers and their physical representation.

\section{Bibliography}

1 Bouchard, C. and Aoussat, A. (1999) 'Computer Aided Design Evolutions in Car Design Process,' September, CSCWD, Université de Compiègnes.

2 Midler, C. (1993), L'Auto qui n'existait pas. Management des Projets et Transformation de l'entreprise. Paris Interéditions.

3 Bouchard, C. (1997) 'Modélisation du Design de Style Automobile. Méthode de Veille Stylistique Adaptée au Design du Composant d'aspect', Thèse de Doctorat de l'Ecole Nationale Supérieure des Arts et Métiers, Option Génie Industriel, Soutenue le 18 Juillet 1997, N : 97-15, Duchamp, R. Directeur de Thèse.

4 Lebahar, J.C. (1986) 'Le Travail de Conception en Architecture: Contraintes et Perspectives Apportées par la C.A.O.', Le travail Humain, tome 49, No. 1, 1986.

5 Birtley, N. (1996) Rapport Interne de Recherche, Université de Coventry.

6 Wang, H. (1995) 'An Approach to Computer-Aided Styling', Design Studies Vol. 16, No. 1, January 1995.

7 Lloyd, P. and Scott, P. (1994) 'Discovering the Design Problem', Design Studies, January, Vol. 15, No. 2.

8 Prost, R. (1992) Conception Architecturale, Une Investigation Méthodologique, Ed. L'Harmattan.

9 Smets, G.J.F. and Overbeeke, C.J. (1995) 'Expressing Tastes in Packages', Design Studies, January, Vol. 16, No. 3.

10 Bouchard, C. and Trassaert, P. (1997) 'Conduite Inter-organizationnelle et Système d'information : Management Réseau par le Systémier Automobile dans le Cadre d'une Co-conception', CIMRE Strasbourg.

11 Sperandio, (1987) La Psychologie en Ergonomie. 
12 Bouchard, C. (1996) Computer-aided Design for Car Builders, CADE'96 Postgraduate Conference, Coventry University, University of Art and Design, Coventry (England).

13 Balayou, J.L. and Volatier, (1995) Logiciel De Visu, P.

14 Tovey, M. 'Form Creation Techniques for Automotive CAD', Design Studies, January Vol. 15 No. 1.

15 Shiroma, Y. (1999) A Study on the Generation of Aleatory Forms by Aleatory, ICED 99 Munich, August 24-26, 1999 Cognitive Activity in Style/Design.

16 Guenand, A. (1999) Semantic Analysis, September, CSCWD, Université de Compiègnes.

17 Wardle, G. Tomorrow's Designer. Combining Sensitivity with Technical Skills. ATA Angegneria Automotoristica.

18 Hatchuel, A. (1994) Apprentissages Collectifs et Activités de Conception, Revue Française de Gestion, Juin-Juillet 1994, pp. 109-120.

19 Beguin, P. (1994) Travailler avec la CAO en Ingénierie Industrielle : de l'individuel au Collectif dans les Activités avec Instruments, Thèse de Doctorat d'Ergonomie, CNAM, Paris.

20 Casper Van Dijk, G. C. New Insights in Computer Aided Conceptual Design, Design Studie Vol. 16, No. 1.

21 Chirowsky, P. (1993) User Interface in Conceptual Generation Design, Design Studie No. 3, Vol. 14, Juin 1993. 